\title{
¿Snow Particle Collection Efficiency and Adjustment Curves for the Hotplate Precipitation Gauge $\mathscr{O}$
}

\author{
Arianna Cauteruccio, ${ }^{a}$ Enrico Chinchella, ${ }^{a}$ Mattia Stagnaro, ${ }^{a}$ And Luca G. Lanza ${ }^{\mathrm{a}, \mathrm{b}}$ \\ ${ }^{a}$ Department of Civil, Chemical and Environmental Engineering, University of Genova, Genoa, Italy \\ ${ }^{\mathrm{b}}$ WMO/CIMO Lead Centre "B. Castelli" on Precipitation Intensity, Genoa, Italy
}

(Manuscript received 16 June 2020, in final form 6 January 2021)

\begin{abstract}
The hotplate precipitation gauge operates by means of a thermodynamic principle. It is composed of a small disk with two thin aluminum heated plates on the upper and lower faces. Each plate has three concentric rings to prevent the hydrometeors from sliding off in strong wind. As for the more widely used tipping-bucket and weighing gauges, measurements are affected by the wind-induced bias due to the bluff-body aerodynamics of the instrument outer shape. Unsteady Reynolds-averaged Navier-Stokes equations were numerically solved, using a $k-\omega$ shear stress transport closure model, to simulate the aerodynamic influence of the gauge body on the airflow. Wind tunnel tests were conducted to validate simulation results. Solid particle trajectories were modeled using a Lagrangian particle tracking model to evaluate the influence of the airflow modification on the ability of the instrument to collect the incoming hydrometeors. A suitable parameterization of the particle size distribution, as a function of the snowfall intensity, was employed to calculate the collection efficiency (CE) under different wind conditions. Results reveal a relevant role of the three rings in enhancing the collection performance of the gauge. Below $7.5 \mathrm{~m} \mathrm{~s}^{-1}$, the CE curves linearly decrease with increasing the wind speed, while beyond that threshold, the blocking caused by the rings counter effects the aerodynamic induced undercatch, and the CE curves quadratically increase with the wind speed. At high wind speed, the undercatch vanishes and the instrument exhibits a rapidly increasing overcatch. For operational purposes, adjustment curves were formulated as a function of the wind speed and the measured snowfall intensity.
\end{abstract}

KEYWORDS: Precipitation; Snowfall; Instrumentation/sensors; Measurements; Wind effects

\section{Introduction}

In situ precipitation measurements using catching type precipitation gauges, like the widely used tipping-bucket and weighing gauges, are affected by catching biases due to the environmental conditions acting at the measurement site. These gauges are equipped with a collector to convey precipitation into a container, where the collected amount of water is measured. The gauge body, immersed in a wind field, behaves like a bluff-body obstacle in the free flow and produces strong velocity gradients, upward components, and turbulence close to the gauge. These effects divert the approaching hydrometeors trajectories and lead to a relevant undercatch, which increases with increasing the wind velocity.

The problem of wind-induced biases on precipitation measurements has been known for at least 160 years. The first clear assessment of the aerodynamic issues in precipitation measurements, recognizing the bluff-body nature of the gauge body when immersed in a wind field, is generally

๑ Denotes content that is immediately available upon publication as open access.

Supplemental information related to this paper is available at the Journals Online website: https://doi.org/10.1175/JHM-D-200149.s1.

Corresponding author: Luca G. Lanza, luca.lanza@unige.it attributed to Jevons (1861), who stated that "the rain-gauge is itself an obstacle, causing the wind to swerve aside, and to change the direction in which the rain-drops fall." Jevons was addressing the difference in precipitation measurements observed when gauges are located at different elevations above the ground level, especially when sited on a rooftop or a tower, and suggested that a gauge with the collector levelled with the surrounding ground (the so-called pit gauge, see EN-13798:2010; EN 2010) would be the only solution to avoid any wind-induced undercatch. After Koschmieder (1934), the wind exposure problem is also termed the "Jevons effect."

This topic is addressed in the literature by means of field measurement campaigns, wind tunnel tests, and numerical simulation. Both field comparisons and wind tunnel experiments require a considerable amount of time to produce valuable results. Moreover, in the field, results are strictly associated with the site climatology (Wolff et al. 2015; Colli et al. 2020) and the actual precipitation is unknown. The World Meteorological Organization (WMO) recommends the use of the Double Fence Intercomparison Reference (DFIR) and the pit gauge as reference installations for solid and liquid precipitation measurements, respectively. In the wind tunnel the real precipitation cannot be reproduced and only a few hydrometeor trajectories can be observed (Green and Helliwell 1972). On the contrary, the numerical simulation approach allows to investigate different configurations by varying the gauge geometry, wind speed and type of precipitation [liquid/solid precipitation, particle size distribution (PSD), and precipitation intensity]. 
In the work of Nešpor and Sevruk (1999), the wind induced bias was evaluated using computational fluid dynamics (CFD) finite-volume simulations to solve the three-dimensional Reynolds-averaged Navier-Stokes (RANS) equations around gauges with cylindrical shape and exploiting the $k-\varepsilon$ turbulence closure model (Jones and Launder 1972). Liquid particle trajectories were calculated by means of a Lagrangian particle tracking (LPT) model, which solves the equations of the particles motion by assuming a constant value of the aerodynamic drag coefficient $\left(C_{D}\right)$ along the trajectory. A thorough validation of the suitability of the LPT model to reproduce the trajectories of liquid particles when deviated by the wind-gauge interaction is provided in the recent experimental work performed in the wind tunnel by Cauteruccio et al. (2020, manuscript submitted to Water Resour. Res.).

This approach was also applied to solid precipitation by Thériault et al. (2012) and by increasing the detail of the computational mesh by Colli et al. (2016a,b). In the literature, indeed, a lot of studies concentrate on solid precipitation because in such case the wind induced bias is more prominent. Thériault et al. (2012) performed RANS simulations with a $k-\varepsilon$ turbulence closure model for a shielded gauge with chimney shape, while in the work of Colli et al. (2016a) both RANS simulations with a $k-\omega$ shear stress transport (SST) turbulence closure model (Wilcox 1988; Menter 1992) and large-eddy simulations (LES) were performed on the same gauge geometry with and without a Single Alter wind shield. Thériault et al. (2012) modeled different crystal types by using a power law parameterization of the terminal velocity, volume, density and cross section of the particles as proposed by Rasmussen et al. (1999), while Colli et al. (2016b) investigated two macro categories: wet and dry snow. Finally, the collection efficiency (CE) curves were calculated by assuming the parameters of the PSD as proposed by Houze et al. (1979) for solid precipitation and results were compared with field observations.

A better fit of the collection efficiency curves with real-world data is shown by Colli et al. (2015), where the snowflake trajectories were calculated by accounting for the dependence of the aerodynamic $C_{D}$ on the local Reynolds number of solid particles $\left(\operatorname{Re}_{p}\right)$. The $\operatorname{Re}_{p}$ of a falling particle is influenced by the instantaneous particle-to-air magnitude of velocity therefore, at each time step, the particle trajectory is obtained by updating the associated drag coefficient. Following these results, a lot of interest was raised in obtaining adjustment curves for the various instruments that compose the networks of precipitation gauges used by meteorological services and for research purposes.

In the present work the aerodynamic effect due to the gauge body-airflow interaction on the collection performance of the Hotplate $^{1}$ precipitation gauge (hereinafter the hotplate) is investigated by following the numerical approach described above.

The hotplate precipitation gauge (Fig. 1) was developed by the Research Applications Laboratory at the National Center for Atmospheric Research in Boulder, Colorado, with the

\footnotetext{
${ }^{1}$ Hotplate is a registered trademark of the University Corporation for Atmospheric Research Foundation.
}

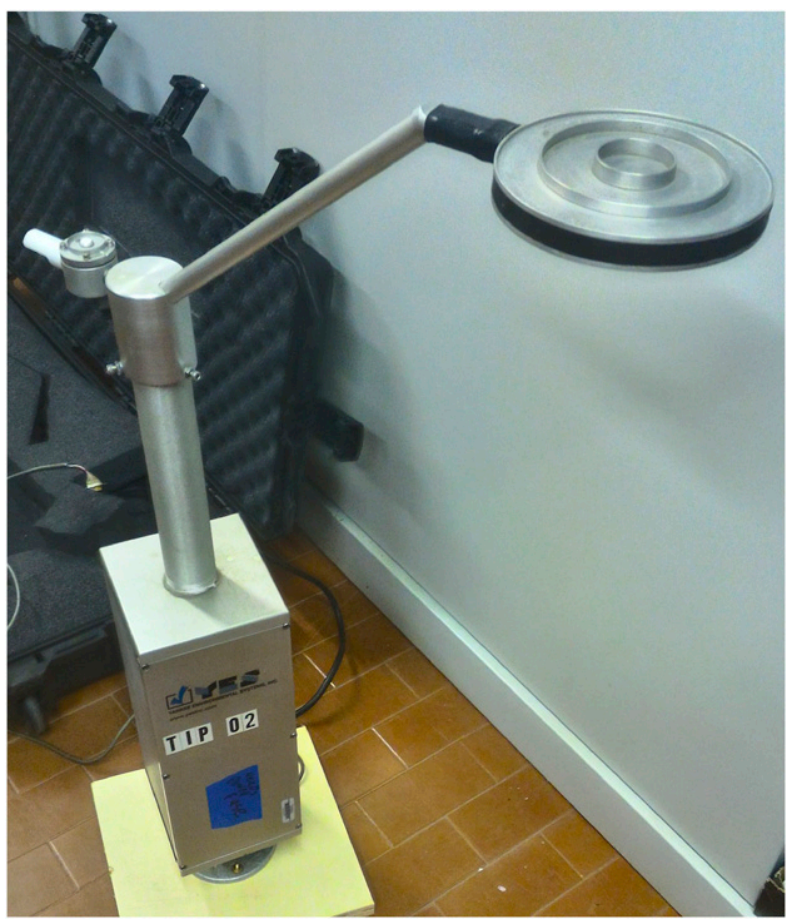

FIG. 1. The hotplate precipitation gauge and a close view of the measuring plate.

intent to obtain a precipitation gauge capable of measuring solid precipitation intensity up to $50 \mathrm{~mm} \mathrm{~h}^{-1}$ in very harsh environmental conditions and requiring little maintenance. The instrument operates by means of a thermodynamic principle (Rasmussen et al. 2011), which dictates its geometry, and is composed by a small disk with a diameter of $13 \mathrm{~cm}$ and two thin aluminum heated plates on the upper and lower faces of the disk. On the plates three concentric rings are installed to prevent the hydrometeors from sliding off during strong wind conditions. Therefore, the collecting area is not a simple projection of the plate surface. Moreover, the instrument is not axisymmetric because the disk is supported laterally by an inclined arm attached to the main circuitry box. As described in the installation and user guide (YES INC. 2011), the upper plate is maintained at $2 \mathrm{~m}$ above the ground surface by mounting the box on a pole. The de-icing effect of the hotplate, which allows the instrument to operate reliably in extreme environmental conditions without requiring frequent maintenance as is typical of weighing gauges (Martinaitis et al. 2015), is fostering its adoption in field measurements.

The hotplate performance was compared against other gauges during different field intercomparison campaigns. For example, it was tested in three different sites during the Solid Precipitation Intercomparison Experiment (SPICE) organized by the World Meteorological Organization (WMO) showing very promising results (Nitu et al. 2018) and was used as a reference for measuring the precipitation volume at the ground level in the Global Precipitation Measurement Cold Season Precipitation Experiment (GCPEX) (Skofronick-Jackson et al. 2015). It was also employed to investigate the 

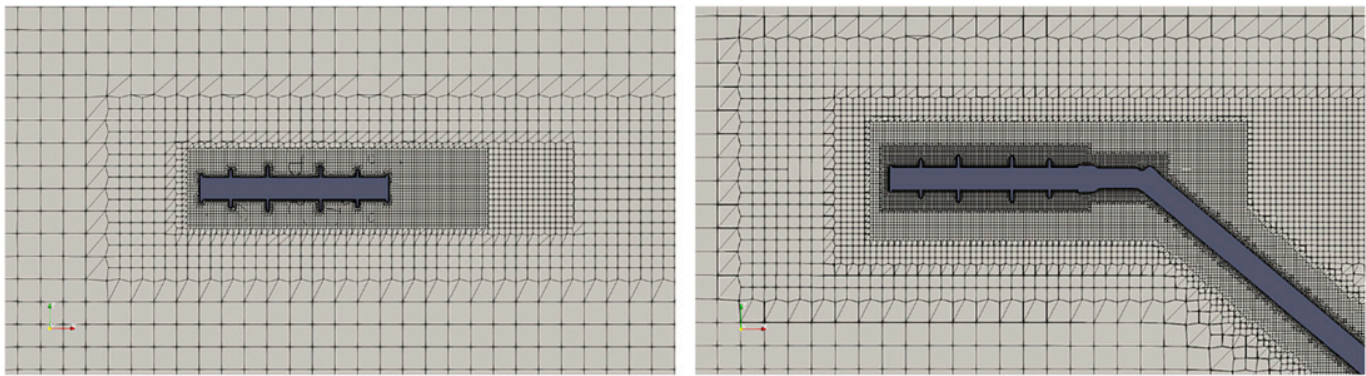

FIG. 2. Details of the computational mesh close to the hotplate surface for the (left) preliminary and (right) the improved fluid dynamic simulations.

correlation between precipitation and visibility (Gultepe and Milbrandt 2010) or the icing phenomenon (Wang et al. 2019). The increasing use of the hotplate also increased the interest in evaluating and correcting the associated measurement biases, for example Zelasko et al. (2018) evaluated the effects of longwave and shortwave radiation on the instrument performance, proposing an alternative algorithm to calculate precipitation intensity.

Rasmussen et al. (2011) derived a wind-speed-dependent collection efficiency related to the instrumental error of the hotplate, although not to its aerodynamic effect as investigated in the present work. Indeed, the measuring principle exploited by the hotplate involves keeping the temperature difference between the upper and lower plates negligible, therefore the effect of wind in cooling the surface of the lower plate-where precipitation is not impacting — must be carefully considered. Since a correction for this effect is integrated on board the instrument control unit, it is reasonable to assume that additional snow particle over/undercatch may be due to aerodynamics effects and that a CFD approach can be used to develop suitable correction curves.

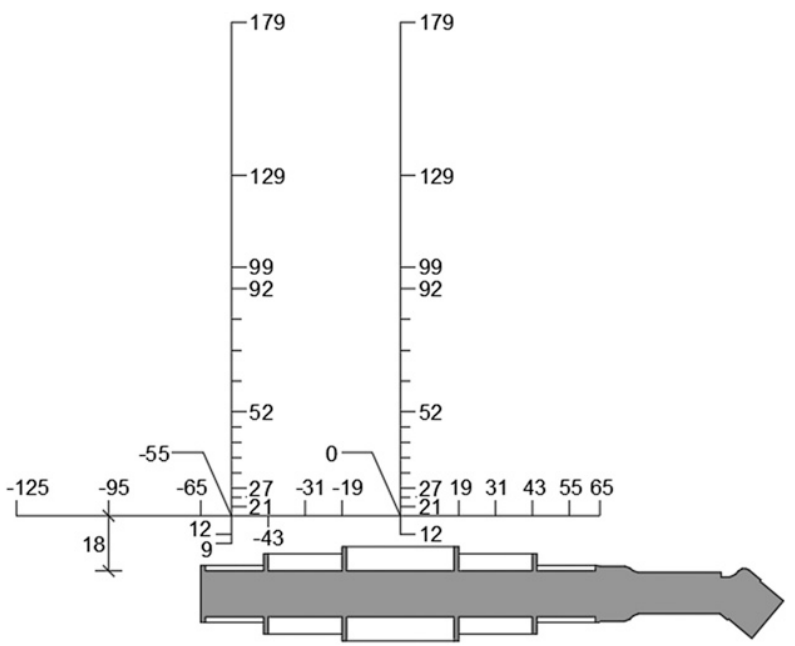

FIG. 3. Positions of the Cobra probe used to measure the local flow velocity in the DICCA wind tunnel, expressed in millimeters, above the upper plate of the hotplate gauge.
In this paper, the CFD simulations performed to calculate the aerodynamic impact of the instrument on the airflow velocity field are described in section 2 . Numerical results were validated by comparison with wind tunnel flow velocity measurements from local measuring probes and a particle image velocimetry (PIV) technique. Using the improved LPT model
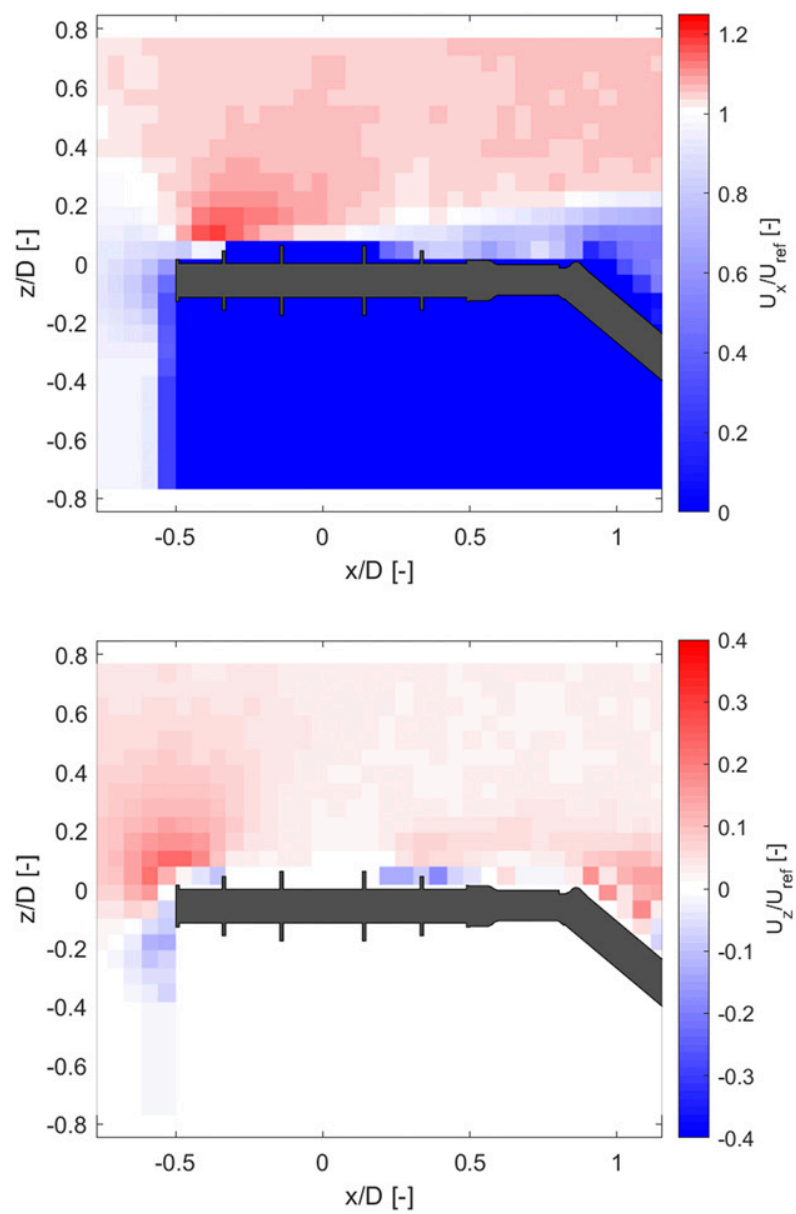

FIG. 4. PIV velocity fields of the normalized (top) horizontal and (bottom) vertical components of the flow velocity along the streamwise direction in the central section $(y / D=0)$ of the hotplate at $U_{\text {ref }}=10 \mathrm{~m} \mathrm{~s}^{-1}$. 


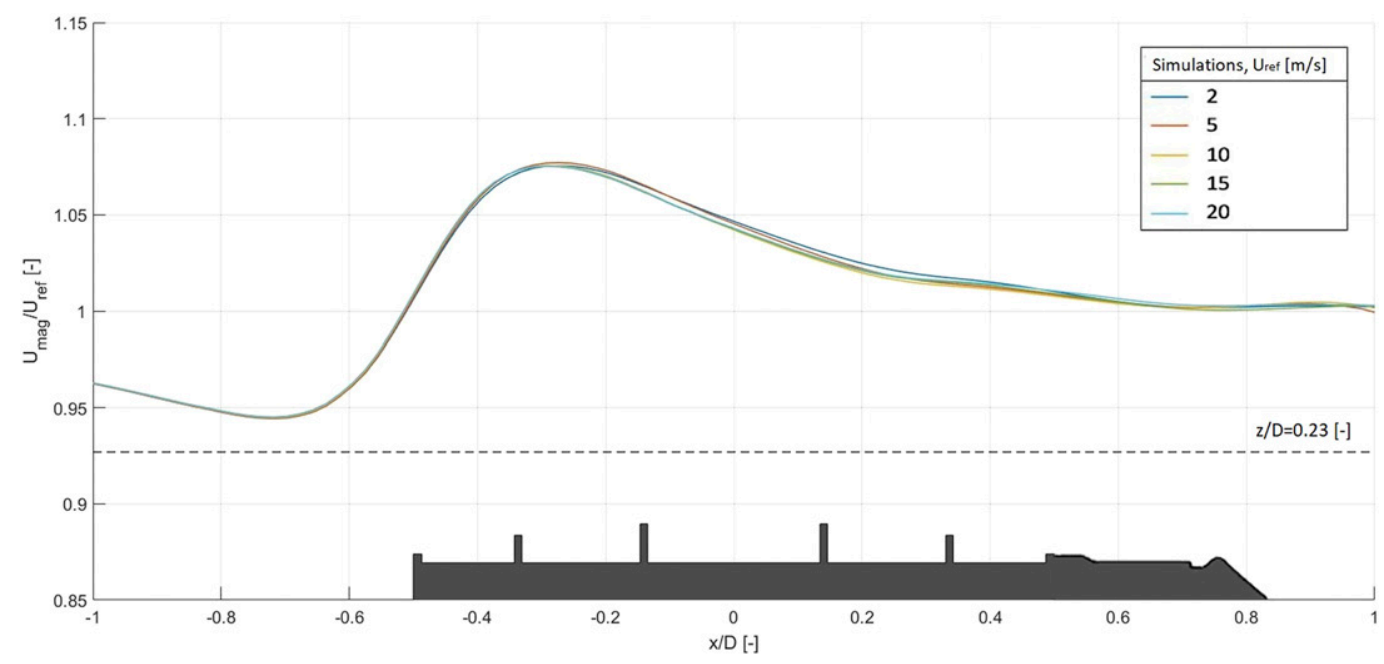

FIG. 5. Comparison between the longitudinal numerical profiles of the normalized flow velocity magnitude, along the streamwise direction at $z / D=0.23$ above the top plate, for each investigated wind speed.

of Colli et al. (2015), collection efficiency curves were calculated as a function of both wind speed $\left(U_{\text {ref }}\right)$ and the actual snowfall intensity (SI). Results are discussed in section 3 where adjustment curves are derived, for operational use, as a function of the measured snowfall intensity $\left(\mathrm{SI}_{\text {meas }}\right)$ and wind speed.

\section{Methodology}

Computational fluid dynamics simulations based on the unsteady Reynolds-averaged Navier-Stokes (URANS) model and the $k-\omega$ SST turbulence closure model (Wilcox 1988; Menter 1992) were performed using the open-source OpenFOAM software package (Greenshields 2020). Due to the specific measurement principle exploited by the hotplate, thermo-fluid dynamic simulations were conducted for various wind speeds by coupling the Navier-Stokes equations with the conservation of energy theorem.

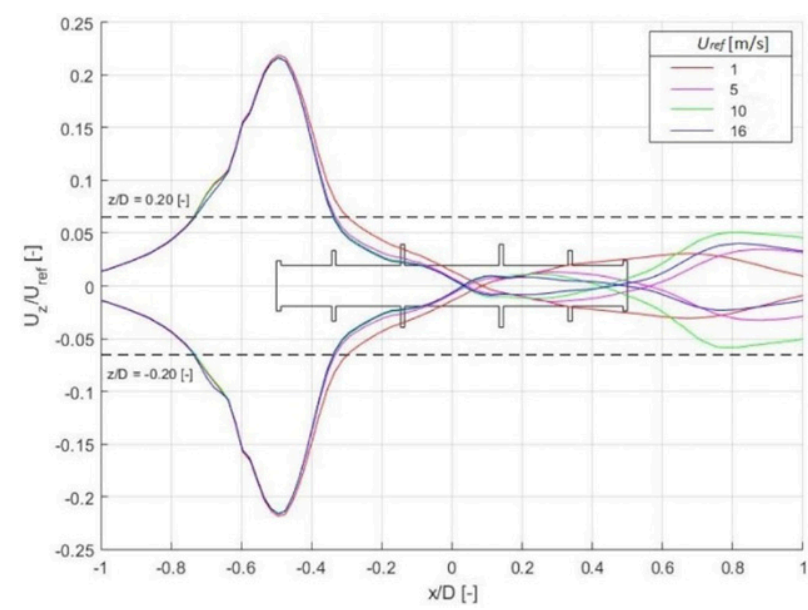

As a first step, both fluid and thermo-fluid dynamic simulations were based on a simplified geometry of the gauge, precisely without the supporting arm, and employed a coarse computational mesh (see Fig. 2, left-hand panel). This preliminary investigation demonstrated, by comparing the resulting flow velocity fields, that the buoyancy effect due to the heated plate on the airflow dynamics is negligible for wind speed larger than $1 \mathrm{~m} \mathrm{~s}^{-1}$. Therefore, in the final configuration, fluid dynamic simulations were performed without solving the conservation of energy theorem, in order to reduce the computational burden, and by completing the gauge geometry with its supporting arm and improving the refinement of the computational mesh (see Fig. 2 right-hand panel). The circuitry box below the hotplate (see Fig. 1) was omitted in the simulated gauge geometry because the distance (along the vertical and horizontal directions) between the upper part of the box and the hotplate is sufficient to avoid any

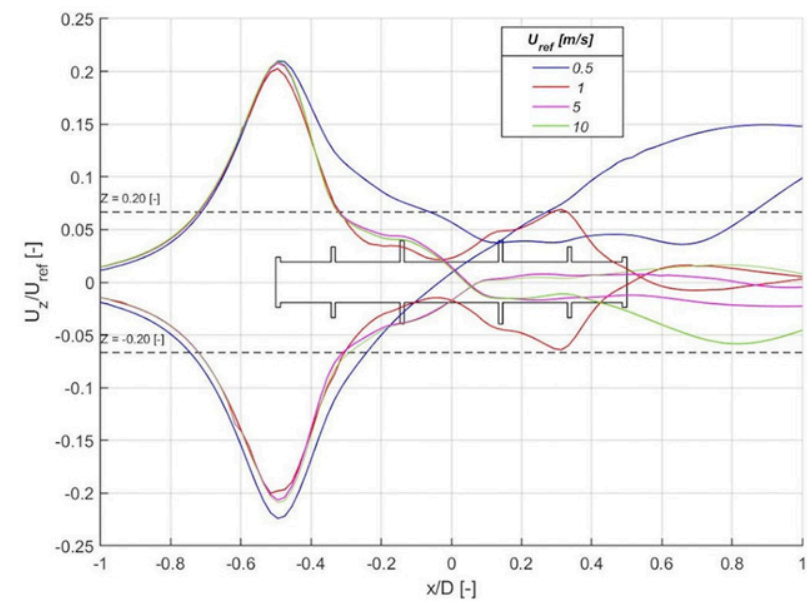

FIG. 6. Comparison between longitudinal profiles of the normalized vertical velocity component $\left(U_{z} / U_{\text {ref }}\right)$ at $z / D= \pm 0.20$ above and below the instrument for (left) fluid and (right) thermo-fluid dynamic simulations. 

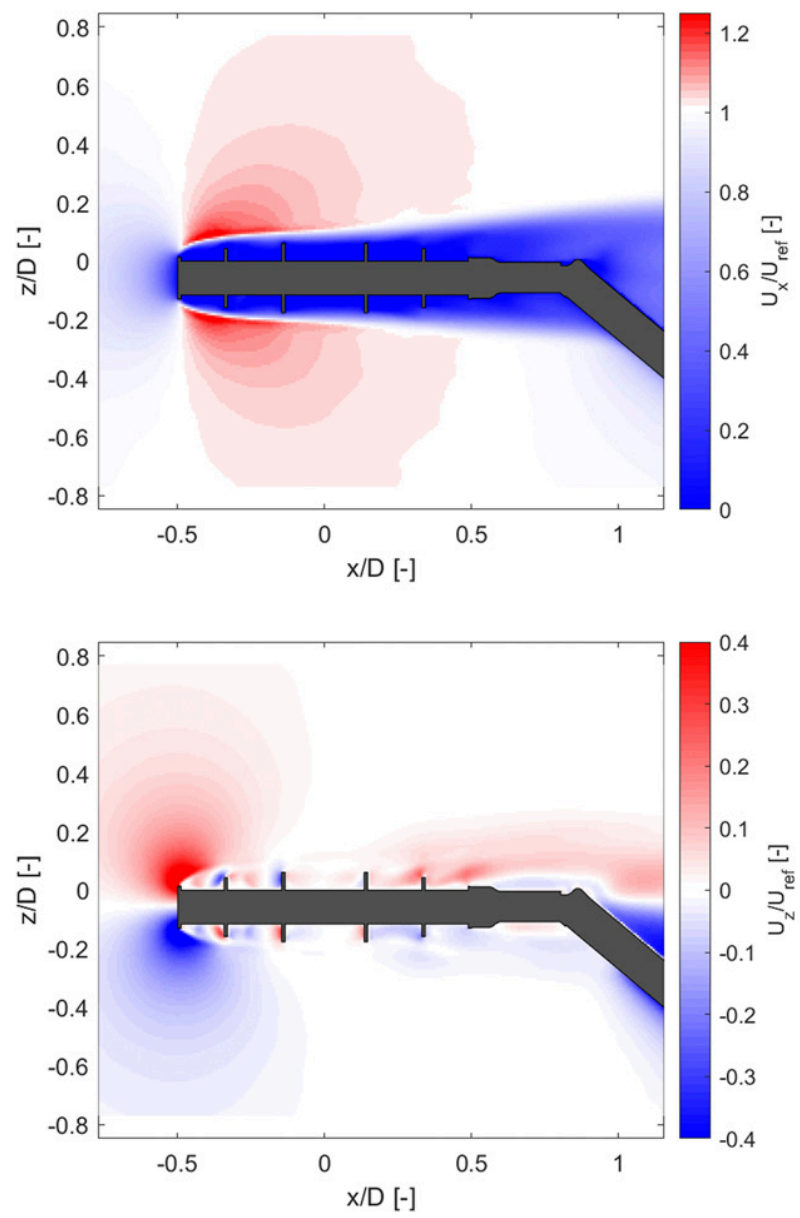

FIG. 7. Normalized velocity fields of the (top) horizontal $\left(U_{x} / U_{\text {ref }}\right)$ and (bottom) vertical $\left(U_{z} / U_{\text {ref }}\right)$ component at $U_{\text {ref }}=10 \mathrm{~m} \mathrm{~s}^{-1}$ in the vertical plane $(x / D, z / D)$ at $y / D=0$ for the configuration with the supporting arm located downwind of the plate $\left(0^{\circ}\right)$.

significant influence on the airflow near the gauge (see, e.g., Sohankar et al. 2017; Sumner et al. 2017).

Probe velocity measurements and PIV allowed validation of numerical results in a wind tunnel experiment, as detailed below. In the first case, a multihole pressure probe named Cobra (Shepherd 1981) was employed and flow velocity measurements were sampled in selected positions close to the gauge, while the PIV provided the flow velocity field along the streamwise direction in the $2 \mathrm{D}$ section centered on the hotplate.

Hydrometeor trajectories were modeled based on the validated airflow velocity fields. The path of each particle was analyzed, considering the complex geometry of the gauge body, to establish whether it is captured by the instrument or not. For various particle size/wind velocity combinations the catch ratio was calculated. The catch ratio $r$ is defined as the ratio between the number of particles captured by the hotplate in disturbed airflow conditions and the number of particles that are expected to hit the horizontal surface area of the disk and rings, should the instrument have no influence on the surrounding airflow. Finally,
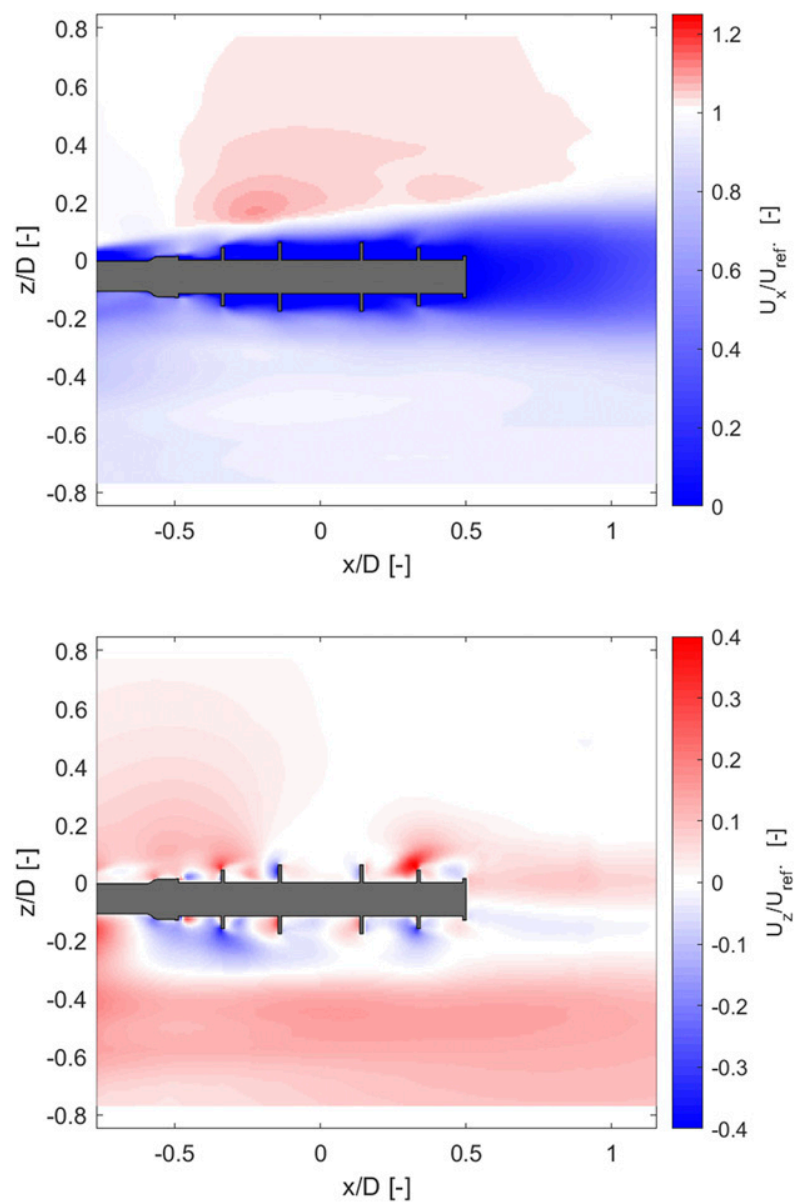

FIG. 8. Normalized velocity fields of the (top) horizontal $\left(U_{x} / U_{\text {ref }}\right)$ and (bottom) vertical $\left(U_{z} / U_{\text {ref }}\right)$ component at $U_{\text {ref }}=10 \mathrm{~m} \mathrm{~s}^{-1}$ in the vertical plane $(x / D, z / D)$ at $y / D=0$ for the configuration with the supporting arm located upwind of the plate $(180)^{\circ}$.

starting from the calculated catch ratios and introducing the dependency of the CE on the snowfall intensity, by means of the PSD parameterization proposed by Gunn and Marshall (1958), the adjustment curves were obtained as a function of wind speed and snowfall intensity.

\section{a. Thermo-fluid and fluid dynamics simulations}

The flow fields (velocity magnitude and components) around the hotplate were calculated by numerically solving finitevolume CFD simulations. The geometry of the hotplate was digitally reproduced in the Standard Triangulation Language (STL) format, suited to generate the computational mesh, and it was divided into three portions (upper plate, inner disk, and bottom plate) in order to assign the appropriate boundary conditions in terms of temperature. In a first step, thermo-fluid dynamic simulations were conducted at reference wind speed $\left(U_{\text {ref }}\right)$, assumed as a uniform and constant boundary condition, equal to $0.5,1,5$, and $10 \mathrm{~m} \mathrm{~s}^{-1}$, while fluid dynamic simulations were performed at $1,5,10$, and $16 \mathrm{~m} \mathrm{~s}^{-1}$.

The computational domain, confined within the inlet, outlet, and four lateral surfaces, was discretized using $7 \times 10^{5}$ 


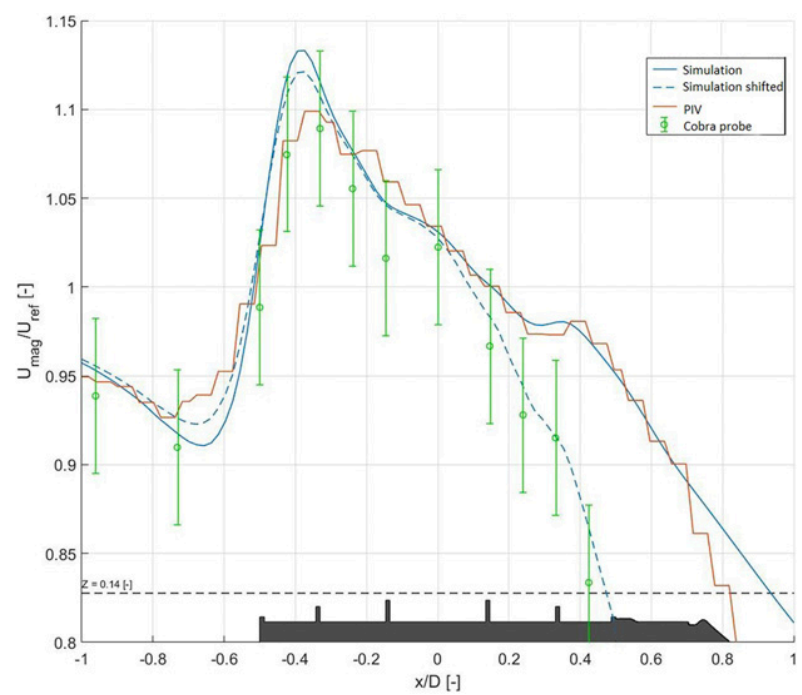

FIG. 9. Comparison between Cobra probe measurements (green circles with uncertainty bars), PIV measurements (red line), and numerical profiles (blue continuous line) of the normalized flow velocity magnitude $\left(U_{\text {mag }} / U_{\text {ref }}\right)$ along the streamwise direction at $z / D=0.14$ and $U_{\text {ref }}=10 \mathrm{~m} \mathrm{~s}^{-1}$. The blue dashed line represents the numerical simulation shifted according to the positioning error occurred during the DICCA WT test.

and $9 \times 10^{5}$ cells for the fluid and thermo-fluid dynamic simulations, respectively.

The three Cartesian coordinates were set with the $x$ axis orientated along the streamwise direction, the $y$ axis along the crosswise direction and the $z$ axis upward. For the thermofluid dynamics simulations, the refinement boxes of the computational mesh around the gauge were stretched upward to better resolve upward air motion due to buoyancy. Thin layers were added on the gauge surface so as to better reproduce the near wall velocity profile.

For fluid dynamic simulations, the fluid air was modeled as a Newtonian incompressible fluid with kinematic viscosity $v_{a}=$ $1.2 \times 10^{-5} \mathrm{~m}^{2} \mathrm{~s}^{-1}$ and density $\rho_{a}=1.3 \mathrm{~kg} \mathrm{~m}^{-3}$ at a reference environmental temperature $T_{a}=0^{\circ} \mathrm{C}$ that acts as the threshold between solid and liquid precipitation. At the inlet of the computational domain $(y-z$ plane $)$ the undisturbed wind speed $U_{\text {ref }}$ was imposed parallel to the $x$ axis and was maintained uniform and constant in time, while a null gradient condition was set for pressure. Atmospheric pressure and null gradient conditions for the velocity were imposed at the outlet $(y-z$ plane opposite to the inlet). The lateral surfaces of the domain were set as symmetry planes. The gauge surface was assumed impermeable with a no-slip condition.

For thermo-fluid dynamic simulations, the air was assumed as a compressible fluid and the initial and boundary conditions were set equal to the previous case with some additional variables: at the inlet of the computational domain the difference between the pressure and the hydrostatic pressure $(\Delta p)$ was set to a fixed flux linked with the velocity value. At the outlet, $\Delta p$ was imposed equal to the atmospheric pressure with a fixed value. A null normal gradient condition for $\Delta p$ was adopted on

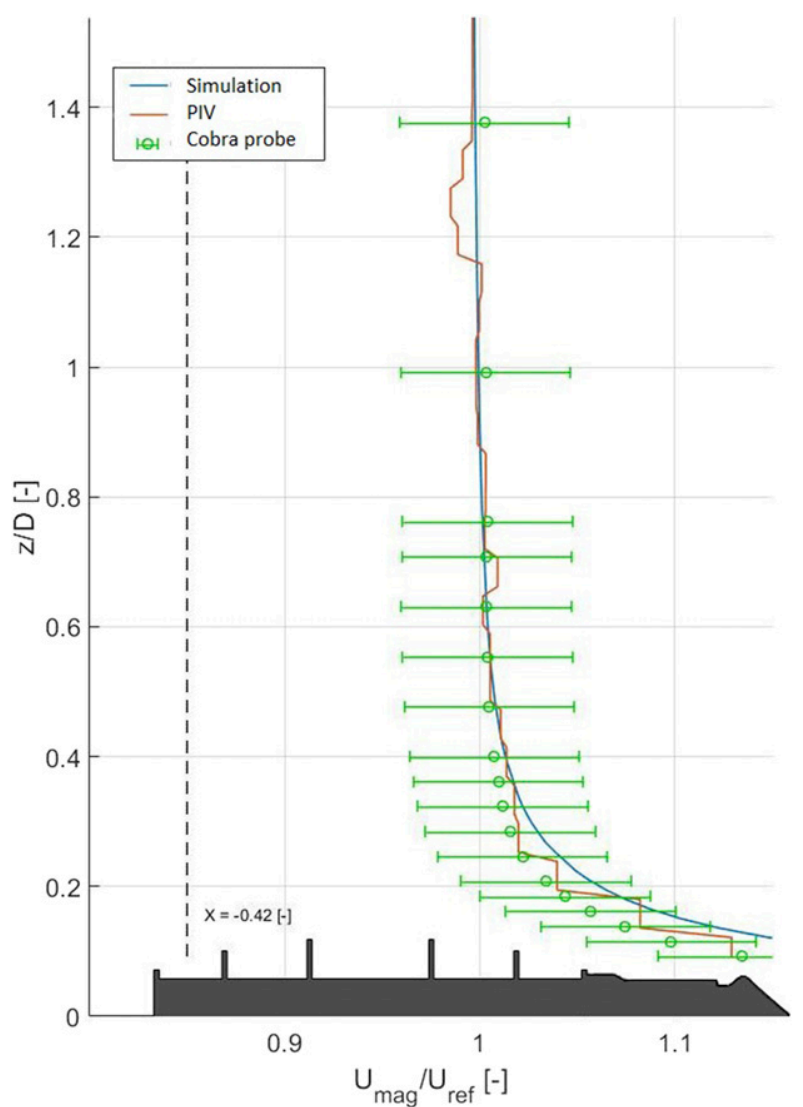

FIG. 10. Comparison between Cobra probe velocity measurements (green circles with uncertainty bars), PIV measurements (red line), and the simulated profile (blue line) for the normalized flow velocity magnitude $\left(U_{\mathrm{mag}} / U_{\mathrm{ref}}\right)$, along the vertical direction at $x / D=-0.42$ and $U_{\text {ref }}=10 \mathrm{~m} \mathrm{~s}^{-1}$.

the hotplate surface. As initial conditions, the temperature of the two plates was fixed equal to $75^{\circ} \mathrm{C}$, while the air temperature was set at $0^{\circ} \mathrm{C}$. The pressure and $\Delta p$ were initially set equal to the atmospheric pressure and zero, respectively.

Based on the preliminary results, standard fluid dynamic simulations were performed, after improving the discretization of the computational mesh and supplementing the geometry with the supporting arm, without solving the conservation of energy theorem. Because of the nonsymmetrical shape of the hotplate and arm assembly, two different configurations were considered, the first one with the supporting arm located downwind of the plate $\left(0^{\circ}\right)$ while the other, rotated by $180^{\circ}$, with the supporting arm positioned upwind of the plate.

URANS simulations for the configuration at $0^{\circ}$ were conducted for wind speed equal to 2, 5, 10, 15 and $20 \mathrm{~m} \mathrm{~s}^{-1}$, while for the geometry rotated by $180^{\circ}$ only a single velocity $\left(U_{\text {ref }}=\right.$ $10 \mathrm{~m} \mathrm{~s}^{-1}$ ) was tested to show the effect of the not fully axisymmetric design of the instrument. All simulations were started using a first-order numerical scheme to ensure the numerical stability that was progressively refined up to a secondorder precision. The computation was performed until a steady state average solution was reached. 

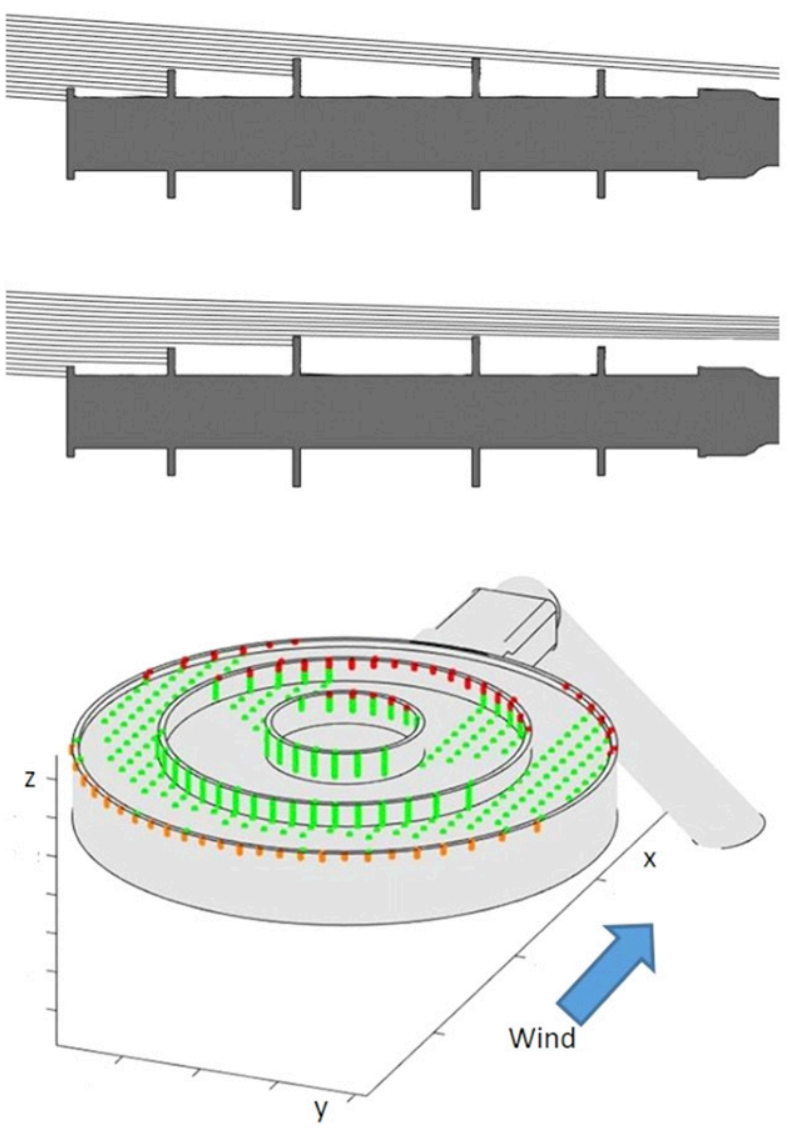

FIG. 11. Simulated trajectories of solid particles $(d=0.25 \mathrm{~mm}$ and $U_{\text {ref }}=10 \mathrm{~m} \mathrm{~s}^{-1}$ ) reaching the hotplate collecting area in (top) undisturbed and (middle) disturbed airflow conditions and (bottom) positions of particles $\left(d=8 \mathrm{~mm}\right.$ and $\left.U_{\text {ref }}=10 \mathrm{~m} \mathrm{~s}^{-1}\right)$ when hitting the hotplate surface. Particles are color coded according to three categories: orange particles should be collected but are blocked by the external ring (resulting in some undecatch), green particles are correctly caught by the hotplate measuring surfaces, and red particles are blocked by the surface of the rings while they should not (resulting in some overcatch).

\section{b. Wind tunnel tests}

The experimental campaign was conducted in the wind tunnel (WT) of the Department of Civil, Chemical and Environmental Engineering (DICCA) of the University of Genoa and in the high-speed test section of the WT facility available at Politecnico di Milano (POLIMI).

A velocity probe and the PIV technique were employed to characterize the flow field around the gauge. The coordinates, in millimetres, of the selected measurement positions of the probe are summarized in Fig. 3. The PIV velocity fields were measured along the axial vertical section of the hotplate, at $y=0$. In both cases the wind velocity was set equal to $10 \mathrm{~m} \mathrm{~s}^{-1}$.

During PIV tests, the WT chamber was uniformly filled with castor oil smoke adopted as a passive tracer. A laser emitter was mounted to the ceiling of the test camber in order to illuminate a vertical section in the $2 \mathrm{D}(x, z)$ plane centered on the hotplate, while the surrounding environment was kept in the dark. The surface of the hotplate was painted in black in order to avoid the reflection of light. A high-speed digital camera, fixed in the tunnel on a rigid pole with its central axis normal to the streamwise direction and centered on the middle of the lateral surface of the hotplate was adopted to record the images of the passive tracer. The local direction and velocity of the particles in the investigated domain were computed by using a cross-correlation algorithm applied to pairs of subsequent images recorded by the video camera. Before running the post processing part of the data, acquired very close to the gauge surface and disturbed by the reflection of light, were masked. The post processing provided the flow velocity maps discretized on a regular grid with cell size of $7.5 \mathrm{~mm} \times 7.5 \mathrm{~mm}$ (see Fig. 4).

\section{c. The particle tracking model}

The LPT model developed by Colli et al. (2015) was here adopted to calculated trajectories of hydrometeors modeled as dry snow particles (Rasmussen et al., 1999; Thériault et al., 2012) with spherical shape of diameter $d=0.25-0.5-0.75 \mathrm{~mm}$ and from 1 to $8 \mathrm{~mm}$, with bin size of $1 \mathrm{~mm}$. Their terminal velocity was obtained by imposing the equilibrium between the acting forces associated with gravity and the aerodynamic drag coefficient, calculated adopting the formulation provided by Khvorostyanov and Curry (2005) for crystals. The density of the simulated particles was modeled in compliance with the power law description reported in the work of Thériault et al. (2012). Dry snow particles were chosen because they are the most sensitive to the airflow features (acceleration, updraft, downdraft, etc.).

The starting positions of the modeled particles are located $1 \mathrm{~m}$ above the upper plate on a regular grid of $0.2 \mathrm{~m} \times 0.3 \mathrm{~m}$, with a spacing of $5 \mathrm{~mm}$. For each wind speed-particle diameter combination a different longitudinal initial position of the center of the grid was calculated, in undisturbed airflow conditions, by computing backward the trajectory of a single particle starting from the center of the upper plate. The velocity of each simulated particle was initialized by imposing the terminal velocity value in the vertical direction, the undisturbed wind speed in the horizontal direction while the transverse component was set equal to zero.

The particle trajectories were computed for the simulated wind velocities $\left(2,5,10,15\right.$, and $\left.20 \mathrm{~m} \mathrm{~s}^{-1}\right)$ and for the rescaled $U_{\text {ref }}=3.5,7.5,12.5$, and $17.5 \mathrm{~m} \mathrm{~s}^{-1}$, thanks to the good scalability of the flow fields as demonstrated by CFD results. Indeed, as illustrated in Fig. 5 at $z / D=0.23$ above the top plate for different wind speeds, the comparison of normalized profiles of the magnitude of flow velocity along the streamwise direction shows that the behavior of the flow remains almost the same while changing the wind speed (low Reynolds dependence).

The catch ratio was computed for each wind velocityparticle size combination. The adopted methodology is based on a discrete number of particle size bins, therefore the same catch ratio is associated to all particle sizes included in each bin. In particular, this assumption allows to account for the contribution of particles with diameter lower than $0.25 \mathrm{~mm}$ on the CE, despite they are not simulated. The impact of this 


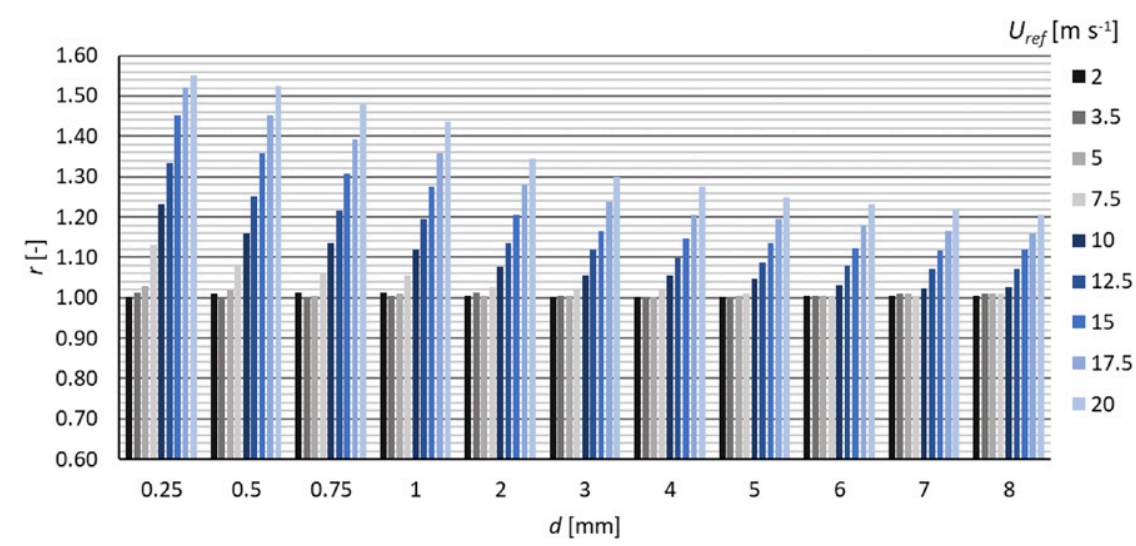

FIG. 12. Comparison between the catch ratios at different wind speeds, for each particle size bin, calculated from the LPT model and based on the undisturbed airflow fields.

simplification is negligible because the contribution of particles smaller than $0.25 \mathrm{~mm}$ on the total water volume is minimal ( $0.5 \%$ for $\mathrm{SI}=1 \mathrm{~mm} \mathrm{~h}^{-1}$ and vanishing with increasing $\left.\mathrm{SI}\right)$. The collection efficiency was calculated by computing the scale parameter $N_{0}$, and the shape parameter $\Lambda$, of the negativeexponential PSD as a function of the SI by following the formulations proposed by Gunn and Marshall (1958) [here reported in Eqs. (1) and (2)] at SI $=0.5,1,2.5,5,10$, and $50 \mathrm{~mm} \mathrm{~h}^{-1}$ :

$$
\begin{aligned}
N_{0} & =3.8 \times 10^{3} \mathrm{SI}^{-0.87}\left(\mathrm{~mm}^{-1} \mathrm{~m}^{-3}\right), \\
\Lambda & =25.5 \mathrm{SI}^{-0.48}\left(\mathrm{~cm}^{-1}\right) .
\end{aligned}
$$

\section{Results and discussion}

\section{a. Validation of the CFD simulations}

The CFD simulation results are shown as comparisons between normalized velocity profiles and maps. Figure 6 reports the longitudinal profiles of the normalized vertical component $\left(U_{z} / U_{\text {ref }}\right)$ of flow velocity at $z / D= \pm 0.20$ above and below the instrument for the fluid and thermo-fluid dynamic simulations (left- and right-hand panel, respectively) performed on the simplified computational mesh and geometry. In the case of fluid dynamic simulations, the velocity profiles for $U_{\text {ref }}=5,10$, and $16 \mathrm{~m} \mathrm{~s}^{-1}$ start to differ from each other in the downwind part of the gauge, where the turbulence level increases due to the gauge body-airflow interaction. Indeed, for $U_{\text {ref }}=1 \mathrm{~m} \mathrm{~s}^{-1}$ the velocity profile is not totally overlapped to the others, even in the upwind part of the instrument.

For thermo-fluid dynamic results (right-hand panel), the velocity profile at the lowest wind speed $\left(U_{\text {ref }}=0.5 \mathrm{~m} \mathrm{~s}^{-1}\right)$ differs from the others and reveals that the buoyancy effect due to the heated plate is only relevant at very low wind speed. Based on these results the heating of the plate is hitherto neglected and the analysis is carried out after increasing the details of the computational mesh and introducing the supporting arm to the geometry.

Sample results of the simulations are shown in Fig. 7 for a wind speed of $10 \mathrm{~m} \mathrm{~s}^{-1}$ in terms of normalized velocity maps

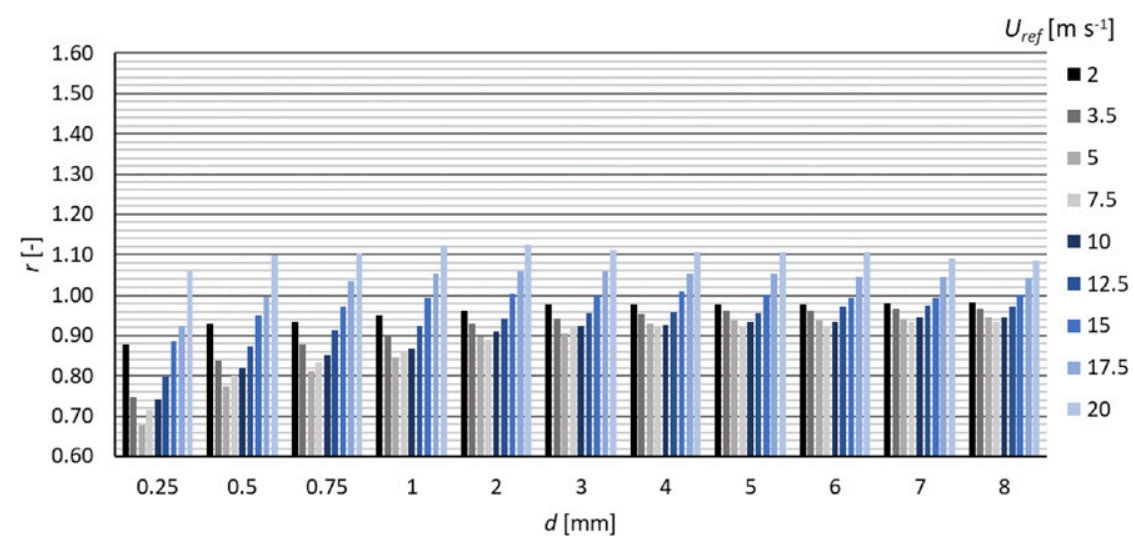

FIG. 13. Comparison between the catch ratios at different wind speeds, for each particle size bin, calculated from the LPT model and based on the URANS simulated or rescaled (disturbed) airflow fields. 


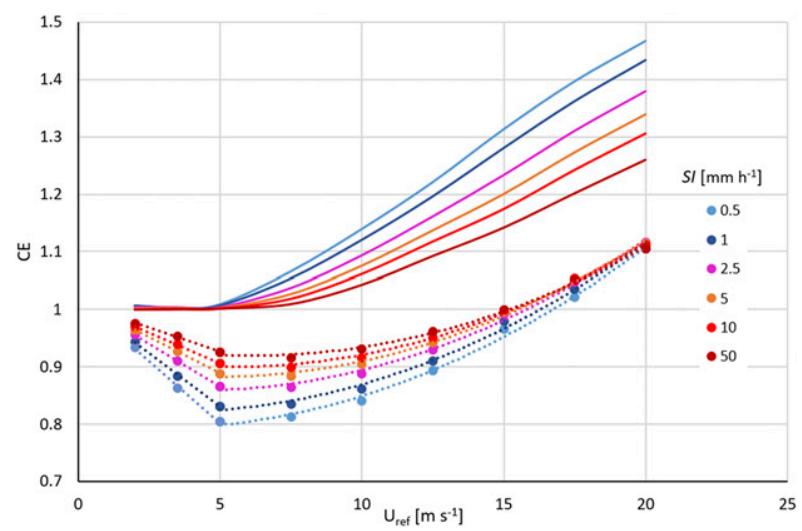

FIG. 14. Geometrical (undisturbed airflow fields, solid lines) and actual (disturbed airflow fields, dotted lines) CE curves for the hotplate precipitation gauge. Circles indicate the results of the performed and rescaled numerical simulations and are color coded according to the snowfall intensity (SI).

for the horizontal $\left(U_{x} / U_{\text {ref }}\right)$ and vertical $\left(U_{z} / U_{\text {ref }}\right)$ components in the vertical plane $(x / D, z / D)$ centered along the direction. The acceleration and updraft regions (red color) around the gauge geometry are evident, with a clear asymmetric pattern due to the presence of the supporting arm. The horizontal component of flow velocity reveals the development of the separation layer (white region), which separates the accelerated zone (red color) from the recirculating one (blue color). A complex pattern of the vertical velocity component appears above the upper plate because of the collecting rings, with an expected impact on the hydrometeor trajectories close to the plate.

When the instrument is positioned in the configuration at $180^{\circ}$ the supporting arm, located upwind of the plate, has the maximum impact on the airflow field around the gauge, and the resulting horizontal and vertical components of the velocity are different from those described above. The normalized fields of the horizontal and vertical velocity components are visualized along the vertical streamwise central section of the computational domain in Fig. 8. By comparing these velocity fields with the ones in Fig. 7, it is evident that the supporting arm does have an influence on the airflow deformation, resulting in lower maximum values of the velocity components.

The validation of the numerical scheme was obtained by comparison with wind tunnel flow velocity measurements. In Fig. 9, a comparison between the longitudinal profiles of the normalized magnitude of the flow velocity $\left(U_{\text {mag }} / U_{\text {ref }}\right)$ at $z / D=$ 0.14 above the top plate as measured by the PIV technique (red line) and calculated by the URANS simulation (blue continuous line) is shown. The relative maximum and minimum of the numerical profile are not caught by the PIV measurements due to the coarse discretization of the spatial domain, when compared with the dimension of the hotplate details (e.g., the thickness of the collecting rings), which introduces a smoothing effect on the measured flow field.

The same numerical velocity profile is compared with the Cobra probe measurements (green circles), from the DICCA dataset. In this case, for a large number of experimental data the simulation does not even fall within the uncertainty limits of the probe measurements (bars). The high velocity gradients generated by the presence of the instrument means that any small error in the probe position, in the order of magnitude of few millimetres, can lead to a significant over or under estimation of the velocity value. Moreover, the longitudinal section at $z / D=0.14$ above the plate intersects the separation layer and is almost completely included in an area of extremely high velocity gradients.

The errors on the positioning were quantified by using a least squares approach, searching for each probe velocity value the shift in 3D spatial coordinates $(d x, d y, d z)$ that minimizes the difference between the numerical velocity profile and each measured value. The obtained shift, suggested that the instrument was slightly tilted upward at an angle $\theta=2.5^{\circ}$ from the horizontal plane when installed in the DICCA wind tunnel. By shifting the simulation according to this result the numerical velocity profile (indicated with a dashed line) is satisfactorily close to the flow measurements, and lies within the uncertainty limits of the probe measurements.

In Fig. 10, the vertical velocity profile at $x / D=-0.42$ of the normalized magnitude of flow velocity $\left(U_{\mathrm{mag}} / U_{\text {ref }}\right)$ calculated from the URANS simulations (blue line) is compared with both the PIV velocity profile (red line) and the local flow velocity measurements (green circles with bars). The simulated profile is well located between the probe measurements and in agreement with the PIV field.

Based on these results we can affirm that the experimental campaign allowed the CFD simulations of the aerodynamic response of the hotplate precipitation gauge to be fully validated, and that such simulations can be used to derive the collection efficiency curves of the gauge as a function of wind speed, precipitation intensity and particle characteristics.

\section{b. Particle tracking and catch ratios}

The presence of the three concentric rings, fixed on the collecting heated plate, is responsible for a significant variation of the collecting area when increasing the wind speed, which is

TABLE 1. Slope and intercept parameters $(m, n)$ of the linear best-fit for $U_{\text {ref }} \leq 5 \mathrm{~m} \mathrm{~s}^{-1}$ at different SI values with the associated correlation factors.

\begin{tabular}{|c|c|c|c|c|c|c|}
\hline \multirow[b]{2}{*}{$\mathrm{SI}\left(\mathrm{mm} \mathrm{h}^{-1}\right)$} & \multicolumn{6}{|c|}{ Linear regression: $\mathrm{CE}=m(\mathrm{SI}) \times U_{\text {ref }}+n(\mathrm{SI})$} \\
\hline & 0.5 & 1 & 2.5 & 5 & 10 & 50 \\
\hline$m$ & -0.043 & -0.0372 & -0.0297 & -0.025 & -0.0213 & -0.0165 \\
\hline$n$ & 1.0174 & 1.0164 & 1.0147 & 1.0138 & 1.0125 & 1.0096 \\
\hline$R^{2}$ & 0.9964 & 0.9986 & 0.9998 & 1 & 0.9993 & 0.9952 \\
\hline
\end{tabular}


TABLE 2. Parameters $(a, b, c)$ of the second-order polynomial best-fit for $U_{\text {ref }} \geq 5 \mathrm{~m} \mathrm{~s}^{-1}$ at different SI values with the associated correlation factors.

\begin{tabular}{|c|c|c|c|c|c|c|}
\hline \multirow[b]{2}{*}{$\mathrm{SI}\left(\mathrm{mm} \mathrm{h}^{-1}\right)$} & \multicolumn{6}{|c|}{ Second-order polynomial: $\mathrm{CE}=a(\mathrm{SI}) \times U_{\text {ref }}^{2}+b(\mathrm{SI}) \times U_{\text {ref }}+c(\mathrm{SI})$} \\
\hline & 0.5 & 1 & 2.5 & 5 & 10 & 50 \\
\hline$a$ & 0.0010 & 0.0010 & 0.0010 & 0.0010 & 0.0010 & 0.0010 \\
\hline$b$ & -0.0056 & -0.0068 & -0.0088 & -0.0101 & -0.0111 & -0.0117 \\
\hline$c$ & 0.8005 & 0.8329 & 0.8778 & 0.9075 & 0.9303 & 0.9456 \\
\hline$R^{2}$ & 0.9956 & 0.9952 & 0.9952 & 0.9955 & 0.9959 & 0.9961 \\
\hline
\end{tabular}

not a simple projection of the plate surface. Note, in the top panel of Fig. 11, that a large number of snowflake trajectories, approaching the hotplate in the central vertical section and simulated by imposing undisturbed airflow conditions, are blocked by the obstruction due to the rings. The same result is shown in the central panel by using the disturbed airflow field in the simulation of the solid particle trajectories. In both cases the wind speed is equal to $10 \mathrm{~m} \mathrm{~s}^{-1}$. From the comparison, the deformation of snowflake trajectories due to the aerodynamic response of the gauge is evident.

The bottom panel of Fig. 11 better explains the effect of the rings on the collection performance of the gauge: the external ring, located on the edge of the gauge, blocks some particles (orange circles) that should be collected (resulting in some undecatch), on the contrary, the internal rings block some trajectories (red circles) that otherwise would be dragged beyond the gauge (resulting in some overcatch). Finally, green particles are those correctly caught by the hotplate measuring surfaces.

The catch ratios reported in Fig. 12 were calculated by assuming undisturbed airflow conditions, and therefore by considering only the geometrical effect of the instrument due to presence of the rings, while those reported in Fig. 13 take into account both the geometrical effect and the aerodynamic disturbance induced by the wind-gauge interaction (the catch ratios are reported in Tables $\mathrm{S} 1$ and $\mathrm{S} 2$ of the online supplemental material). In the first case, the catch ratios for all particle diameters are equal or larger than one. In disturbed airflow conditions, for wind speed from 2 to $5 \mathrm{~m} \mathrm{~s}^{-1}$ the catch ratio decreases, as is typical of the traditional tipping-bucket gauges (usually characterized by cylindrical shape) and weighing gauges (usually with "chimney" shape), then the catch ratio starts to increase with the wind speed and reaches the value $r=1$ at $U_{\text {ref }}=15 \mathrm{~m} \mathrm{~s}^{-1}$ for particle sizes larger than $1 \mathrm{~mm}$. At high wind speed, the geometrical effect becomes predominant and is larger than one for all particle sizes.

\section{c. Collection efficiency and adjustment curves}

In Fig. 14, the geometrical collection efficiency curves calculated from the undisturbed airflow fields and SI $=0.5,1$, $2.5,5,10$, and $50 \mathrm{~mm} \mathrm{~h}^{-1}$ are shown with continuous lines. Whichever the wind speed, an overcatch is observed with increasing values beyond approximately $5 \mathrm{~m} \mathrm{~s}^{-1}$, while by increasing SI the geometrical overcatch decreases. The $\mathrm{CE}$ values calculated for both simulated and rescaled (disturbed) airflow fields are indicated by the circles. For each SI value, identified with the color coding, the CE decreases linearly up to $U_{\text {ref }}=5 \mathrm{~m} \mathrm{~s}^{-1}$, while for wind speed larger than $5 \mathrm{~m} \mathrm{~s}^{-1}$ the CE starts to increase quadratically because of the increasing contribution of the geometrical effect, which derives from the catch ratios being larger than one for each particle size (Fig. 12). For wind speed larger than $15 \mathrm{~m} \mathrm{~s}^{-1}$ the geometrical effect becomes predominant and an overcatch appears for high SI values, and the CE progressively becomes larger than one even for low SI. When the gauge is rotated by $180^{\circ}$ and the airflow impacts on the supporting arm before reaching the
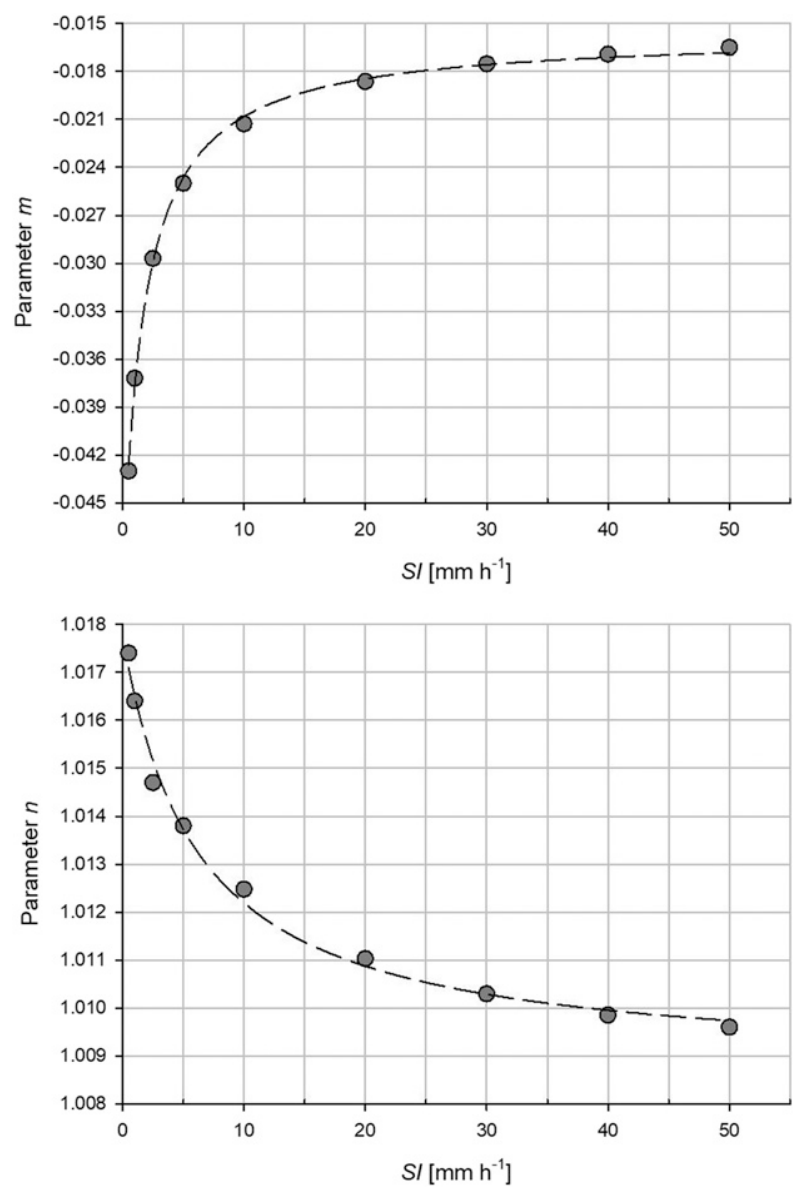

FIG. 15. Trends of the (top) slope $(m)$ and (bottom) intercept (n) parameters with SI for the linear portion of the CE curves. Dashed lines are the inverse second-order polynomial and power law best-fit curves. 
TABLE 3. Coefficients of the hyperbolic best-fit curves for the dependency of $m, n, b$, and $c$ on SI.

\begin{tabular}{lrrrr}
\hline \hline \multicolumn{5}{c}{ Hyperbolic: $m, n, b, c=\frac{p \mathrm{SI}}{q+\mathrm{SI}}+y_{0}$} \\
\\
\hline$m$ & $n$ & $b$ & $c$ \\
\hline$p$ & 0.0347 & -0.0090 & -0.0087 & 0.2063 \\
$q$ & 1.7464 & 6.1576 & 1.7588 & 1.7790 \\
$y_{0}$ & -0.0504 & 1.0178 & -0.0037 & 0.7566 \\
$R^{2}$ & 0.9987 & 0.9931 & 1.000 & 0.9995 \\
\hline
\end{tabular}

hotplate body, the CE calculated for $\mathrm{SI}=50 \mathrm{~mm} \mathrm{~h}^{-1}$, and $U_{\text {ref }}=10 \mathrm{~m} \mathrm{~s}^{-1}$, is $0.5 \%$ higher.

The shape of the CE curve differs from the sigmoidal curve, typical of the cylindrical and chimney-shaped gauges, due to the complex geometry of the hotplate. For each SI category the $\mathrm{CE}$ values were fitted with a linear function for wind speed between 2 and $5 \mathrm{~m} \mathrm{~s}^{-1}$, while a second-order polynomial was adopted for $U_{\text {ref }} \geq 5 \mathrm{~m} \mathrm{~s}^{-1}$. Their best fit parameters are listed in Tables 1 and 2 for each SI category, together with the associated correlation factors.

Note that, contrary to the geometrical CE, the actual CE curves move upward with increasing SI (progressively showing a lower undercatch) and they become closer, implying a reduced dependency on the precipitation intensity at high SI. Also, the dependency on SI reduces with increasing wind speed until, at high wind speed, it vanishes due to the more uniform distribution of the catch ratios through the particle diameters range (see Fig. 13). Indeed, at high wind speed, the trajectories of particles of whatever size tend to be very flat over the horizontal, so that the catch ratios are very similar to each other because of the relevant role of the rings in blocking such particles (with a predominant geometrical effect on the $\mathrm{CE}$ ).

With the objective to obtain an easy to use adjustment curve, as a function of wind speed and the precipitation intensity measured by the gauge, as suggested by Colli et al. (2020) and Cauteruccio (2020), the dependency of the CE curves on SI was made explicit in the coefficients of both the linear and the quadratic portions. To better fit the numerical results, the $\mathrm{CE}$ values were calculated for further intermediate intensity levels, between those reported in Fig. 14, specifically at 20, 30, and $40 \mathrm{~mm} \mathrm{~h}^{-1}$. The dependency of the slope $(m)$ and intercept $(n)$ parameters of the linear portion of the CE on SI is depicted in the top and bottom panels of Fig. 15, respectively. The parameters of their hyperbolic best-fit curves are listed in Table 3 . These results reveal that the dependency of the CE curve on SI tends to reduce with increasing SI, confirming the reduced distance between contiguous curves as observed in Fig. 14 at progressively higher SI.

As for the quadratic portion of the CE curves, it can be noted from Table 2 that the parameter $a$ is constant for all CE curves at any SI level, indicating that the degree of curvature of the best-fit quadratic function is the same. The parameters $b$ and $c$ are depicted as a function of SI in the top and bottom panels of Fig. 16, respectively. The parameters of their hyperbolic bestfit curves are listed in Table 3. Similar to the linear portion of the CE curves, also the parameters of the quadratic portion
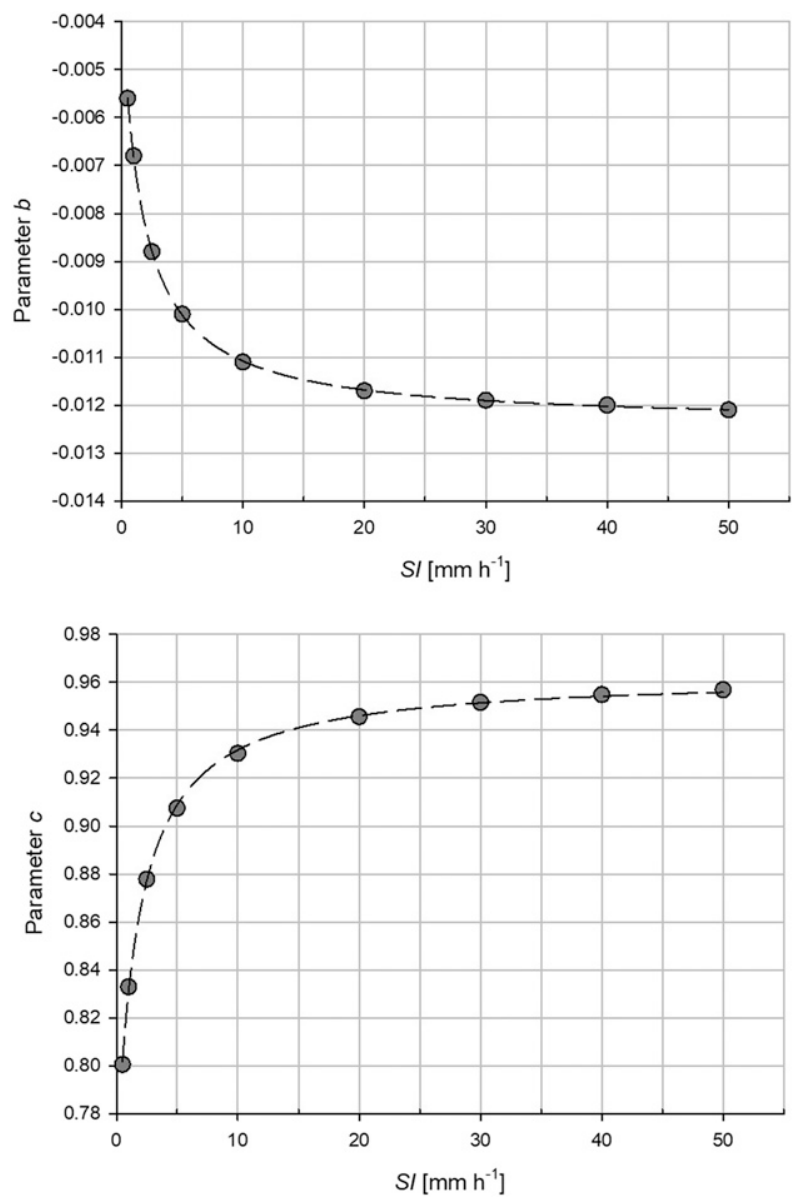

FIG. 16. Trends of the (top) $b$ and (bottom) $c$ parameters with SI for the quadratic portion of the CE curves. Dashed lines are the inverse second-order polynomial best-fit curves.

reveal that the dependency of the CE curve on SI tends to reduce with increasing SI.

While the CE curves illustrated in Fig. 14 provide a clear picture of the behavior of the instrument under different wind speed and SI conditions, they are hardly applicable in this form for operational use. Indeed, their construction steps from the knowledge of the reference (actual) SI, which is unknown in the real world. Adjustment curves were therefore derived with the aim to provide a useful tool that can be used operationally to apply a correction for the wind-induced bias when only wind speed and the measured snowfall intensity $\left(\mathrm{SI}_{\text {meas }}\right)$ are known. Numerical results for the simulated and rescaled airflow fields are therefore reported in Fig. 17 in a $\left(\mathrm{SI}_{\text {meas }}, \mathrm{SI}\right)$ graph, together with their two parameters power law best-fit curves. The parameters of the adjustment curves are summarized in Table 4, where for all curves the correlation factor $\left(R^{2}\right)$ is equal to one.

Some overcatch is obtained at high wind speed, while undercatch starts to be observed when the wind speed is lower than $15 \mathrm{~m} \mathrm{~s}^{-1}$, as already discussed above. Note that the exponent of the power law best-fit curves, $t$, approaches one when increasing the wind speed, as it was also clear from Fig. 14 

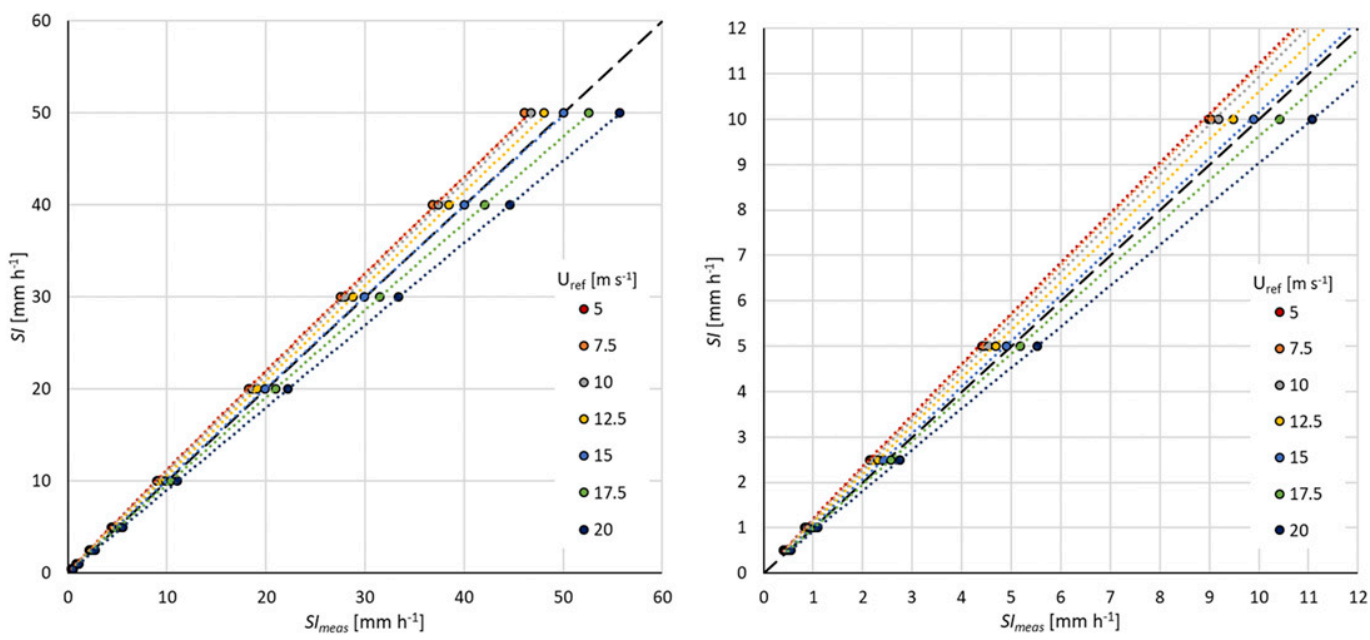

FIG. 17. Adjustment curves (dotted lines) for the hotplate gauge (left) at various wind speeds larger than $5 \mathrm{~m} \mathrm{~s}^{-1}$ and (right) enlargement over the SI range $0-12 \mathrm{~mm} \mathrm{~h}^{-1}$. The diagonal dashed line indicates optimal performance, therefore $\mathrm{CE}=1$, while circles indicate the numerical results of the performed and rescaled simulations, color coded according to the wind speed $U_{\text {ref }}$.

where the circles indicating the different SI levels collapse onto the same $\mathrm{CE}$ value as the wind speed increases, while they are dispersed across a range of $\mathrm{CE}$ values at low wind speed. At $15 \mathrm{~m} \mathrm{~s}^{-1}$ also the multiplicative coefficient $s$ of the power law approaches one to indicate that the $\mathrm{CE}$ value also equals one, and the adjustment curve coincides with the diagonal in the $\left(\mathrm{SI}_{\text {meas }}, \mathrm{SI}\right)$ graph of Fig. 17. In the left-hand panel of Fig. 17 the whole range of $S I$ considered is shown, therefore the correction performed in the low intensity range is hardly appreciable. The range $0-12 \mathrm{~mm} \mathrm{~h}^{-1}$ is enlarged in the right-hand panel to show that an adjustment of about $10 \%$ is necessary for both the undercatch, observed at low wind speed, and the overcatch at high wind speed.

\section{Conclusions}

In this work, the wind effect on the hotplate precipitation gauge measurements was investigated by following a numerical approach. CFD simulations at various wind speed and orientations were conducted to calculate the airflow velocity fields used as input to model hydrometeor trajectories by means of a LPT model. Results, shown in terms of catch ratio and collection efficiency values, demonstrate the role of the particular geometry of the instruments on the collection performance.

The resulting collection efficiency curve shows that the wind induced bias is limited, with a maximum value below $20 \%$ for all wind speeds and precipitation intensities. Also, the shape of the resulting collection efficiency curves is peculiar with respect to the typical curves obtained for cylindrical and chimney-shaped gauges. Adjustment curves as a function of the measured snowfall intensity are proposed to be used for operational purposes in order to correct realworld measurements by using wind velocity observations alone as the ancillary variable required to perform the adjustment.
The collection efficiency values here obtained from numerical simulation are fairly consistent with the experimental observations collected during the WMO-SPICE at various sites with different climatology. As reported in Nitu et al. (2018) during SPICE, the hotplate was compared against the DFIR showing median collection efficiency values between 0.5 and 1.3 at all three sites at which it was tested [Haukeliseter (Norway), Marshall (United States), Sodankylä (Finland)]. The observed collection efficiency is more consistent with our simulations at high wind speed (beyond $7 \mathrm{~m} \mathrm{~s}^{-1}$ ), although with a large spread, while at low wind speed some overcatch is observed in the field, especially in the Sodankylä site. This could be due to the effect of the heating, here neglected, that in very low wind speed conditions may partially melt the snowflakes, increasing their vertical velocity and therefore collection.

Another aspect that may slightly affect the CE and is not considered in this work, is the possibility that a few dry snowflakes slide or bounce off the plate under high wind conditions. This may introduce some additional undercatch that is not contemplated here and, at least partially, explain the difference with the CE obtained by Rasmussen et al. (2011) from field experiments. Note also that, in those field experiments, the actual snowfall intensity is unknown (while it is a datum in the numerical calculation of the $\mathrm{CE}$ ) and measurements from the DFIR are used as the reference. The DFIR, however, has its own bias when impacted by the wind as demonstrated in

TABLE 4. Multiplicative coefficient $s$ and exponent $t$ of the best-fit power laws for the adjustment curves at various wind speeds.

\begin{tabular}{cccccccc}
\hline \multicolumn{7}{c}{ Power law: SI $=s \times\left(\mathrm{SI}_{\text {meas }}\right)^{t}$} \\
\hline$U_{\text {ref }}\left(\mathrm{m} \mathrm{s}^{-1}\right)$ & 5 & 7.5 & 10 & 12.5 & 15 & 17.5 & 20 \\
\hline$s$ & 1.202 & 1.184 & 1.150 & 1.103 & 1.045 & 0.981 & 0.913 \\
$t$ & 0.970 & 0.974 & 0.978 & 0.983 & 0.987 & 0.991 & 0.995 \\
\hline
\end{tabular}


Thériault et al. (2015), which also depends on the wind direction since the geometry of the DFIR is not symmetric.

Higher values of the $\mathrm{CE}$ are expected in case the hotplate is impacted by wind from the opposite direction than the one used to derive the $\mathrm{CE}$ curves, as indicated by the simulation performed at $180^{\circ}$, suggesting the relevance of the wind direction in assessing the instrument performance against field measurements.

Acknowledgments. This work was developed in the framework of the Italian national project PRIN20154WX5NA "Reconciling precipitation with runoff: the role of understated measurement biases in the modelling of hydrological processes" and as partial fulfilment of the $\mathrm{PhD}$ thesis of the first author.

Data availability statement. The catch ratios reported in Figs. 12 and 13 and used for the CE calculation are available (Tables S1 and S2, respectively) in the online supplement material.

\section{REFERENCES}

Cauteruccio, A., 2020: The role of turbulence in particle-fluid interaction as induced by the outer geometry of catchingtype precipitation gauges. Ph.D. thesis, University of Genova, $162 \mathrm{pp}$.

Colli, M., L. G. Lanza, R. Rasmussen, J. M. Thériault, B. C. Baker, and J. Kochendorfer, 2015: An improved trajectory model to evaluate the collection performance of snow gauges. J. Appl. Meteor. Climatol., 54, 1826-1836, https:// doi.org/10.1175/JAMC-D-15-0035.1.

$\ldots, \ldots, \ldots$, and $\_$, 2016a: The collection efficiency of shielded and unshielded precipitation gauges. Part I: CFD airflow modelling. J. Hydrometeor., 17, 231-243, https:// doi.org/10.1175/JHM-D-15-0010.1.

$\_,-, \ldots$, and $\_, 2016 \mathrm{~b}$ : The collection efficiency of unshielded precipitation gauges. Part II: Modeling particle trajectories. J. Hydrometeor., 17, 245-255, https://doi.org/ 10.1175/JHM-D-15-0011.1.

-, M. Stagnaro, L. G. Lanza, R. Rasmussen, and J. M. Thériault, 2020: Adjustments for wind-induced undercatch in snowfall measurements based on precipitation intensity. J. Hydrometeor., 21, 1039-1050, https://doi.org/10.1175/ JHM-D-19-0222.1.

EN, 2010: Hydrometry - Specification for a reference raingauge pit. European Committee for Standardization, EN 13798:2010.

Green, M. J., and P. R. Helliwell, 1972: The effect of wind on the rainfall catch. Distribution of precipitation in mountainous areas, World Meteorological Organization Rep. 326, Vol. 2, 27-46.

Greenshields, C. J., 2020: OpenFOAM User Guide, v. 8.., The OpenFOAM Foundation Ltd, 243 pp., https://openfoam.org/.

Gultepe, I., and J. A. Milbrandt, 2010: Probabilistic parameterizations of visibility using observations of rain precipitation rate, relative humidity, and visibility. J. Appl. Meteor. Climatol., 49, 36-46, https://doi.org/10.1175/2009JAMC1927.1.

Gunn, K. L. S., and J. S. Marshall, 1958: The distribution with size of aggregate snowflakes. J. Meteor., 15, 452-461, https://doi.org/10.1175/1520-0469(1958)015<0452:TDWSOA $>$ 2.0.CO;2.

Houze, R. A., P. V. Hobbs, P. H. Herzegh, and D. B. Parsons, 1979: Size distributions of precipitation particles in frontal clouds. J. Atmos. Sci., 36, 156-162, https://doi.org/10.1175/ 1520-0469(1979)036<0156:SDOPPI $>2.0 . C O ; 2$.

Jevons, W. S., 1861: On the deficiency of rain in an elevated rain-gauge, as caused by wind. London Edinb. Dublin Philos. Mag. J. Sci., 22, 421-433, https://doi.org/10.1080/ 14786446108643180.

Jones, W. P., and B. E. Launder, 1972: The prediction of laminarization with a two-equation model of turbulence. Int. J. Heat Mass Transf., 15, 301-314, https://doi.org/10.1016/ 0017-9310(72)90076-2.

Khvorostyanov, V. I., and J. A. Curry, 2005: Fall velocities of hydrometeors in the atmosphere: Refinements to a continuous analytical power law. J. Atmos. Sci., 62, 4343-4357, https:// doi.org/10.1175/JAS3622.1.

Koschmieder, H., 1934: Methods and results of definite rain measurements. Mon. Wea. Rev., 62, 5-7, https://doi.org/10.1175/ 1520-0493(1934)62<5:MARODR $>2.0 . C O ; 2$.

Martinaitis, S. M., S. B. Cocks, Y. Qi, B. T. Kaney, J. Zhang, and K. Howard, 2015: Understanding winter precipitation impacts on automated gauge observations within a real-time system. J. Hydrometeor., 16, 2345-2363, https://doi.org/ 10.1175/JHM-D-15-0020.1.

Menter, F. R., 1992: Improve two-equation $k-\omega$ turbulence models for aerodynamic flows. NASA Tech. Memo. 103975, $31 \mathrm{pp}$, https://ntrs.nasa.gov/citations/19930013620.

Nešpor, V., and B. Sevruk, 1999: Estimation of wind-induced error of rainfall gauge measurements using a numerical simulation. J. Atmos. Oceanic Technol., 16, 450-464, https://doi.org/ 10.1175/1520-0426(1999)016<0450:EOWIEO > 2.0.CO;2.

Nitu, R., and Coauthors, 2018: WMO Solid Precipitation Intercomparison Experiment (SPICE) (2012-2015). IOM Rep. 131, World Meteorological Organization, 1445 pp., https://library.wmo.int/doc_num.php?explnum_id=5686.

Rasmussen, R. M., J. Vivekanandan, J. Cole, and B. M. C. Masters, 1999: The estimation of snowfall rate using visibility. J. Appl. Meteor., 38, 1542-1563, https://doi.org/10.1175/ 1520-0450(1999)038<1542:TEOSRU > 2.0.CO;2.

—, J. Hallett, R. Purcell, S. Landolt, and J. Cole, 2011: The hotplate precipitation gauge. J. Atmos. Oceanic Technol., 28, 148-164, https://doi.org/10.1175/2010JTECHA1375.1.

Shepherd, I. C., 1981: A four hole pressure probe for fluid flow measurements in three dimensions. J. Fluids Eng., 103, 590-594, https://doi.org/10.1115/1.3241774.

Skofronick-Jackson, G., and Coauthors, 2015: Global Precipitation Measurement Cold Season Precipitation Experiment (GCPEX): For measurement's sake, let it snow. Bull. Amer. Meteor. Soc., 96, 1719-1741, https://doi.org/10.1175/BAMS-D-13-00262.1.

Sohankar, A., M. K. Esfeh, H. Pourjafari, M. M. Alam, and L. Wang, 2017: Feature of the flow over a finite length square cylinder on a wall at various incidence angles. Wind Struct., 26, 317-329, https://doi.org/10.12989/was.2018.26.5.317.

Sumner, D., N. Rostamy, D. J. Bergstrom, and J. D. Bugg, 2017: Influence of aspect ratio on the mean flow field of a surface-mounted finite-height square prism. Int. J. Heat Fluid Flow, 65, 1-20, https://doi.org/10.1016/j.ijheatfluidflow. 2017.02.004.

Thériault, J. M., R. Rasmussen, K. Ikeda, and S. Landolt, 2012: Dependence of snow gauge collection efficiency on snowflake characteristics. J. Appl. Meteor. Climatol., 51, 745-762, https:// doi.org/10.1175/JAMC-D-11-0116.1.

- — - E. Petro, J. Y. Trépanier, M. Colli, and L. G. Lanza, 2015: Impact of wind direction, wind speed, and particle characteristics on the collection efficiency of the double fence 
intercomparison reference. J. Appl. Meteor. Climatol., 54, 1918-1930, https://doi.org/10.1175/JAMC-D-15-0034.1.

Wang, T., S. Niu, J. Lü, and Y. Zhou, 2019: Observational study on the supercooled fog droplet spectrum distribution and icing accumulation mechanism in Lushan, Southeast China. $A d v$. Atmos. Sci., 36, 29-40, https://doi.org/10.1007/s00376-018-8017-6.

Wilcox, D. C., 1988: Reassessment of the scale-determining equation for advanced turbulence models. AIAA J., 26, 1299-1310, https://doi.org/10.2514/3.10041.

Wolff, M. A., K. Isaksen, A. Petersen-Øverleir, K. Ødemark, T. Reitan, and R. Brækkan, 2015: Derivation of a new continuous adjustment function for correcting wind-induced loss of solid precipitation: Results of a Norwegian field study. Hydrol. Earth Syst. Sci., 19, 951-967, https://doi.org/10.5194/ hess-19-951-2015.

YES INC., 2011: TPS-3100 Total Precipitation Sensor, Installation and User Guide, Version 2.0, Rev M, 43 pp.

Zelasko, N., A. Wettlaufer, B. Borkhuu, M. Burkhart, L. S. Campbell, W. J. Steenburgh, and J. R. Snider, 2018: Hotplate precipitation gauge calibrations and field measurements. Atmos. Meas. Tech., 11, 441-458, https://doi.org/10.5194/ amt-11-441-2018. 